\title{
Leisure time: Behavioural Factors, Course of Life and Lifestyle
}

\author{
George F. Zarotis and Walter Tokarski
}

\begin{abstract}
Leisure cannot be perceived as a phenomenon that affects all people to the same degree. General statistical trends such as more time, higher available disposable income or technical innovations cannot lead to the conclusion that every member of the society changes its leisure activities in the same way and adapts to the new framework conditions. Whether and how individual social differences affect leisure time, are reproduced or transformed in view of current sociopolitical changes continues to be a particularly topical question in the study of leisure time and lifestyle. The ultimate goal of this research is the analysis of behavioural factors, the course of life and lifestyle as regards leisure time. The method adopted for the study was a review of the relevant literature. In the light of the present study, it is found that a differentiated view of leisure behaviour should essentially be followed from two complementary perspectives: a theory of action and a theory of structure. This action occurs in a social structure, which specifies a place of action for the individual, in which the individual actions are consciously or unconsciously adapted. The analysis of social structures to date can be made more precise. Lifestyles are mainly distinguished by the activities they contain. This means creating a style that results from everyday visible actions and ways of behaving. Orientations are also taken into consideration, which could lead to the conclusion on which principles people organize their lives. Lifestyle, in a nutshell, can be understood as a thematically structured model of providing motivation, perceptions, behaviour and experience in order to meet needs, accomplish tasks, and reach or achieve goals.
\end{abstract}

From the social sciences point of view, it has been shown that lifestyle expression depends on demographic factors that are not influenced, such as age and gender, as well as social factors such as education, occupational status and income. As a result, we can maintain that the change trends as regards leisure time that were discussed here undoubtedly provide a good basis for estimating leisure activities. Adequate time and financial resources are essential to this end.

Index Terms-Leisure Time, Behavioural Factors, Life Course, Lifestyle.

\section{INTRODUCTION}

At the beginning of the systematic research on leisure time, in the 1950s and 1960s, most of the time - almost like the proposition hiding behind this - it was set as a basis that leisure can be explained by a number of defined variables. These so-called determinant ideas initially recognized that knowledge of only very few variables - most often Sociodemographic - was sufficient to define and explain leisure. According to what was aforementioned, age,

Published on April 16, 2020.

G. F. Zarotis is with University of the Aegean, Faculty of Human Sciences, Rhodes, Greece. (Corresponding Author, e-mail: drgzarotis@tonline.de, zarotisg@rhodes.aegean.gr)

W. Tokarski is with German Sport University, Cologne, Germany. education, and the fact of employment were the decisive factors. On the other hand, gender, type of profession, position in the life cycle and place of residence had the least decisive power and only car and income had a small decisive power. In the 1970s, these ideas expanded into psychological, physiological, and other social determinants. The focus on leisure behaviour that was hitherto prevalent was also abandoned, and leisure was perceived as a module providing motivation, interests, behaviour and experiences in leisure time. This development, which has been particularly observed in the United States and less in Germany, has led to an examination of leisure-time in relation to work, to the degree of the freedom that work permits, to the motivation and importance of a leisure activity as well as to goal orientation. From the perspective of Leisure Psychology, the determinants based on Psychology of Personality, Social and Evolutionary Psychology are of crucial importance. In the light of Social Psychology, the focus was mainly on aspects of family, occupational status and residence, as well as social contact. The role of family and professional socialization, the appropriateness of home with respect to leisure time as well as the living environment and the role of relationships' networks were examined. The perception of leisure in terms of Evolutionary Psychology is not widely established. Because chronological age, in leisure time, is not a reliable indicator of changes due to evolution, longitudinal studies were needed to adequately investigate these changes. The existing research over time shows rather steady trends in leisure biographies, namely there were no major changes in the structure of individual leisure time with the course of life or in longer periods of life. After all, most of these surveys were carried out 20 years ago and mainly deal with the behaviour towards leisure time. But more recent studies in the field of Sport Psychology and Gerontology-Psychology show that leisure time in people of middle and older ages is initially low compared to younger ages. However, later that changes to a large extent; at this point changes in the environment of hygiene, social, ecological, economic and / or mental nature are of importance.

Behind the variety of leisure activities there are also a variety of motivations. Regarding the dependency of the incentives that are important for leisure time on social characteristics, the major determinant lies in the attributes 'position in the life cycle' and 'integration into social groups'. Leisure incentives need to be differentiated from both leisure needs and leisure functions, although these three concepts are closely intertwined and define each other: While leisure needs are generally broadly defined by categories such as self-esteem, creativity, rest, social contact, etc., leisure incentives understandably refer to 
certain leisure activities and their functions: leisure incentives state something more specific than leisure needs, they characterize the events that trigger a behaviour, maintain it, and direct it to a specific goal. Therefore, leisure incentives are highly dependent on the situation. Again, there is need to distinguish between these and leisure functions. While leisure incentives are concerned with the "key aspect" of leisure behaviour, leisure functions refer to the "goal aspect ", that is, the satisfaction that a particular behaviour brings. If, for example, you look at the field of leisure "movement, play and sport", which is of the utmost importance to people in our society, from the motivation point of view it, there seems to be a wide range, from compensating for daily commitments, achieving performance, striving for good health, to fun, communication and demonstration. Leisure time and recreation in Germany is primarily a matter of the federal states and the communities. The Federation only has an indirect effect on leisure by creating framework conditions which allow the individuals to freely configure their leisure time and to establish leisure time facilities. This is done by law provisions, general government programs, model designs, and more. The implementation of such initiatives lies in the federal states and communities, such as the preparation of action plans for specific social groups, the creation of public green spaces, sports and leisure facilities, the establishment of cultural institutions and leisure centres or even the provision of land for the establishment of commercial facilities for leisure time. In Germany, leisure policy is not an independent policy sector, but rather a matter of various policy sectors such as housing and urban planning, rural policy, social and family policy, labour and health policy, and transport and economic policy. In particular, overtime policy (reductions in working hours up to 35 hours a week, extended holidays, flexible retirement age, part-time job creation) over the last 50 years has led to a huge increase in subjective importance of free time for the individual. Leisure time cannot be isolated from the other aspects of a person's life. Until now, there has not been a unilateral correlation, as regards quality and direction, between leisure-time behaviour and leisure-time experience, and other areas of life. However, restorative behaviour does not play the major role that is often cited in the relevant literature (ZAROTIS et al. 2011; FREERICKS \& BRINKMANN, 2015).

\section{Methodology}

The present study is a bibliographical survey study that presents the critical points of existing knowledge about a theoretical approach to the topic of "Leisure Time: Behavioural Factors, Course of Life and Lifestyle".

There is no specialized and comprehensive research in this area. This study attempts to fill this gap and may be a useful aid for those who will make similar efforts in the future. The main objective of the bibliographical review is to integrate the study into the "body" of the subject in question. The review of the current study refers to clearly formulated questions and uses systematic and explicit criteria for the critical analysis of a published paper by summarizing, sorting, grouping and comparing.

\section{Bibliographic REVIEW STUDY}

\section{A. Behavioural Factors in Leisure Time}

It is beyond dispute that leisure time behaviour is the leisure category most frequently examined scientifically. Often the analysis of leisure time behaviour is exactly the same as the analysis of leisure time. At this point, it can be overlooked that behaviour is simply a quantitative element of leisure time, from which alone very few conclusions can be drawn without examining qualitative elements such as motivation for leisure time, perceptions of leisure time and experience of leisure time. When comparing the existing results regarding leisure time activities in Germany for more than 40 years, the following leisure time patterns become apparent: Television emerges during the 50ies and over time becomes the primary leisure time activity, defending successfully this top position against other traditional media (newspapers, magazines, radio) until today. The importance of new media has been increasing for some years, but to date it does not exceed 15\%. Travel and outdoor activities saw a sharp increase in the 50ies and 60ies and then somewhat declined. The importance of sports, fitness and health is also increasing, but for some years they have stabilized at around $35 \%$. Since leisure time research started, cultural activities have been at the bottom of the scale. If these results are broken down into social groups then sports, gaming, media use and attending events are significantly higher among children and adolescents than the average of the general population. Something similar applies to older people in terms of healthy activities, housework and gardening, reading and taking care of children or grandchildren (DGF, 1998, 2000). The growth of single households in modern society has a strong effect in leisure time as well. Young people studying, people without a steady relationship but also an increasing number of older people who have lost their life partner are considered single. Their solitary existence leads to highly personalized leisure time habits because they no longer steadily coexist with a partner. People who live alone use part of their leisure time activities to maintain or create social contacts due to lack of a partner. Many single people focus their leisure time activities on partner search (DIETRICH, HEINEMANN, \& SCHUBERT, 1990). Another factor affecting leisure-time behaviour is the higher educational level (RITTNER, MRAZEK, \& MEIER, 1989; HEINEMANN, 1989). About $50 \%$ of the population has a high school diploma (junior or senior high). The percentage of workers continues to decline, while the percentage of employees is increasing and women are also increasingly employed (DIETRICH, HEINEMANN \& SCHUBERT, 1990). The development of leisure time after World War II was accompanied by a particularly high economic output. Even if we take into account the real increase in prices this still means a fivefold increase in real wages (OPASCHOWSKI, 2008). This increase in economic well-being causes the percentage redistribution of expenses in the family budget. There is less need to spend money on essentials. Instead, an increasing amount of money is spent on the "free" or "increased" need (FREYER, 2001). The better the economic boundary conditions, the higher the need for leisure time activities. In Tokarski \& Schmitz-Scherzer (1985) this means: "Leisure 
time activities are more often accumulated where the portion of income available for leisure time is higher" (TOKARSKI \& SCHMITZ-SCHERZER, 1985, 81). But with increased income, not only does the frequency of activities change, but also the quality of leisure time. Thus, Wachenfeld (1989) finds a significant reduction in the frequency of leisure time activities such as walking, television and inactivity or rest. On the other hand, activities such as reading, short trips, visiting cultural events and sports are more often preferred by people who have available leisure time and are in good financial shape. It is estimated that the available part of income increased from $39 \%$ once to $50 \%$ of total income (DIETRICH, 1990). Maintenance consumption, that is, the demand for essential commodities, does not increase disproportionately or hardly at all with an increase in income. On the contrary when the income is rising there is a proportionate or disproportionate demand for luxury goods. This living consumption is not a major need for survival, but it does make life "happier, more beautiful and richer in experience." As wages and incomes rise and the increase in prices is not the same or higher, living consumption increases faster than maintenance consumption. Leisure time activities are an important part of living consumption, because if there was need, one could waive them if they needed money and time to meet significant for living necessities. Opaschowski (2012) observes an increasing expenditure on leisure time across all income categories, which spend about two monthly incomes a year for leisure time. Material limitations of leisure time in addition to disposable income are also determined by the living environment and mobility. The living environment is important when the person that has leisure time also has only limited mobility. Thus, 'local identity' can be promoted if institutions for culture, recreation and sociality are accessible in the immediate environment (TOKARSKI \& SCHMITZ-SCHERZER, 1985). Since leisure time is particularly important for the majority of people, the place of residence is also chosen on the basis of the charm of its leisure time infrastructure. Leisure time behaviour is also the result of the influence of science and technique. It was only with the increasing use of technique that production processes became more efficient, thus it was possible to achieve greater profits and reduce working time. Technical breakthroughs have also entered leisure time itself and have contributed to the creation of new forms of leisure time, such as television, video, computers, mountain bicycles, surfboards, etc. With the influence of the media, broad strata of the population are participating in this leisure time revolution. Mostly television installed technology in the private living room and thus helped to change behaviour during leisure time (FREYER, 2002). Domestic appliances such as washer, dryer, dishwasher, microwave etc., are nowadays an essential part of the modern household. They simplify housework and thus contribute to a third time gain in having more leisure time. Workplace stress is generally reduced with the use of machinery and occupations with high physical demands become increasingly rare (OPASCHOWSKI, 2008). Science with its knowledge also affects human behaviour during leisure time; just remember the improved medical health care. This has also contributed to the increased health awareness in society. Health aware people are also trying to shape their leisure time towards health, for example by healthy sports or relaxation techniques. Also, the knowledge that man, as a social being, needs contact and support from other people is transferred by many people to leisure time. Without the evolution of the economy, prosperity, and therefore leisure time, cannot be guaranteed. Economy constitutes a guarantee for the behaviour during leisure time and for the formation of leisure time. This is why leisure time and economy in modern societies have a complementary character. "The evolution of leisure time, the reduction of working time needed for it and the availability of the necessary means are not possible without the corresponding growth of the economy... As a social free space, leisure time requires private and public financial security with the availability of resources, the allocation of time and the availability of innovative opportunities." (AGRICOLA, HAAG, \& STOFFERS, 1990, 19). In the meantime, leisure time has become an economic factor in itself. How great the economic asset of leisure time will become in the future depends to a significant degree on the effects of the current economic crisis on leisure time as a factor which cannot yet be predicted at this time. The importance of leisure time, consumption and work varies across age groups. $88 \%$ of young people between the ages of 14-17 consider leisure time important for their well-being while for $65 \%$ of them consumption is important. Work is important for only $44 \%$ of young people. At the ages of 30-49 the values for leisure and consumption are $74 \%$ and $53 \%$ respectively, while the importance of work in this group is significantly higher at $72 \%$. Rankings change in people over 65 and older. They rate leisure time as important at $49 \%$, work at $40 \%$ and consumption at $39 \%$ (OPASCHOWSKI, 2012). From these results we can conclude that younger people can be mobilized much more strongly with leisure time consumption offers based on their lower income. Middle age is more critical of consumption, and while it considers leisure time important, it is no longer dominant. People of this age because of their higher income can benefit from more expensive leisure time offers. In older people, leisure time and consumption may not be so highly valued, but this does not necessarily mean that they cannot respond to ageappropriate offers. The complexity of the relationship between leisure time, sport and the economy in today's society becomes particularly clear if the changing of these values is attributed to the partial shift from industry to service delivery. Increasing prosperity, increasing leisure time and innovative satisfaction in the leisure time economy have allowed the leisure time market to become an independent economic sector or economic factor of particular importance. One important sub-market in the leisure time market is the sports market. Differences in the sport subsystem have led to the large expansion of the leisure time service sector. The reasons for this are on one hand the new awareness of leisure time, which is associated with a more favourable economic development, with the increase in leisure time and also with the willingness to spend money on forming leisure time. The increase in the provision of sports services is attributed to overall social developments. But this is the main reason for the higher individual demand. Athletic consumers prefer quality value 
products and personalized service provision in comfortable facilities with 'professional' supervision (AGRICOLA, HAAG \& STOFFERS, 1990). Therefore, lifestyle perceptions constitute a further development of perceptions to date, as they include material and cultural aspects of life as well as individual modes of action. Although there are social inequalities, lifestyles can evolve with externalized moods of action (habit) and the social field in which one moves (interaction) and thus develop a leisure-time behaviour with which each person transcends social boundaries.

\section{B. Leisure Time across the Course of Life}

There are essentially two possibilities to deal with the topic of "Leisure Time across the Course of Life".

1. One possibility is to look at the prospect of age, that is to look at childhood, adolescence, middle and older age, as far as possible in combination with other socio-demographic characteristics, and to find the resulting differences in individual age groups. That can be done with both primary (empirical) and secondary analysis and it will give us access to age differences. Most of the time these are declared ad hoc; perhaps the results and conclusions that result from them have to do with changes in the course of life. But as this is usually the result of analyses without further investigation, it cannot be considered certain. Typical illustrations of the course of life resulting from this approach are as follows: The curves fall - with slight fluctuations and few exceptions - as the age increases; there are decreasing, increasing, or fluctuating trends depending on motivation or sport on vacation. Most leisure activities generally have corresponding curves. We can only make assumptions as to why this happens. The final result of such surveys is most often the need for more intense and in-depth research.

2. What this approach cannot offer is obvious, therefore we turn to the second possibility, namely to answer the questions: exactly what changes take place across the course of life (and one is certain: changes do take place), why they take place, the significance of these changes, what factors are involved, how these changes are experienced, how a person experiences these changes, etc. These are essentially the interesting and important questions raised by the topic "Leisure Time in the Course of Life". But due to lack of studies, the answer is not possible. Certainly, it is already known that today we are living in an age of more free time and multifaceted possibilities for leisure time. These opportunities are welcomed, and not only by the younger generations. All studies about the formation of leisure time show that there are virtually countless possibilities for leisure time activity. In any case, we live in a leisureoriented society, that is, leisure did not replace work with its social significance. Today's leisure time, that is so characterized, presents at the same time some indications of lawlessness and deviation, that is, signs of an increasing lack of rules and types, leading to situations of mass derogatory behaviour, such as the use of violence to impose one's interests or to resolve conflicts. al., 2011).

The more elaborate and enlightening these descriptions of today's leisure time are, the less they are appropriate for an examination from the perspective of the course of life. Other considerations are needed for this purpose, which unfortunately are not often found in the relevant literature. The following five points play a role in this issue (TOKARSKI, 1995a). They are summarized in view of the question about the role and functions of leisure time. According to them:

1. Leisure time encompasses these situations of action, which are dominated by expressive orientations, that is, orientations referring to a self-serving objective, personal expression and confused roles. Although leisure situations are also used according to organic criteria, that is, as means for other purposes, these incentives most of the time fall back on expressive motivation.

2. Leisure time is the central area of expression, where individuality is ensured. There also appears a tendency of social groups to withdraw from the public eye (term: retreat in privacy). In addition, participation in diverse communities and federations in the form of associations, clubs, initiatives, groups and networks of leisure time becomes more important (term: retreat in semi-publicity).

3. Leisure is the central domain for structuring and developing lifestyles, but at the same time for achieving a balance between personal and social identity (TOKARSKI, 1989). These include forms of social change and personalization as well as opportunities for pluralism.

4. Leisure is a highly valued individual resource, which can only be marginally replaced and serves to produce a quality of life.

5. Leisure time, together with work, is one of the dimensions of daily life organization and therefore regulates behaviour.

From the above it is made clear that leisure time performs individual and social function, which is often underestimated. Unfortunately, to date there is no comprehensive analysis of leisure in this regard. The points presented all have a dynamic effect on leisure time. The categories described, expressiveness, retreat in privacy, lifestyle management, life quality creation and daily life structuring, are dynamic. Combined with these, leisure time becomes an important key to the course of life. The question of leisure time in the course of life, therefore, conceals the dynamic aspect of leisure, a view that correlates processes, changes and developments of the leisure experience with the passage of time and across generations. If one analyses the scant existing international literature, no clear picture emerges (TOKARSKI, 1988). The question about specific lifestyles' courses in the course of life and age essentially reveals two trends: on the one hand, there is the tendency to decrease activities, abilities, performance, opportunities for experiences etc., as well as a bankruptcy of life in leisure time for adolescents and young adults - to middle-aged and older people, on the other hand, there is the tendency for 
stability ranging from middle aged to older people. Testimonies for a stable life in leisure time for a long time prevail in the relevant literature. The older the age, for example, the more consistent are the standards for participation in sports (ROBERTS et al., 1991).

But this also applies to other leisure time activities. There is rarely evidence of an increase in activity, quality of experience or performance as age increases, or change, with the exception of the transition from childhood and adolescence to adulthood. Overall evidence of leisure time in the course of life is the tendency for stability and continuity, as one might call it, or that of steady decline. Studies conducted for shorter periods of time, which most often refer to transitional phases, reinforce these testimonies. Here, the aggregate analyses are far superior. Frogner (1991) presented in detail what types of research, ideas and theories these testimonies refer to. These are descriptive studies and statistics, which vary according to age and other socio-demographic characteristics, as well as the analysis of leisure and sports careers through phase systems as 'prestages' of the statement on lifelong sport, further socialization theories, within which learning theories and plans for the course of life (life cycle, life period, age) and motivation theories play a special role (FROGNER, 1991).

\section{Leisure Time and Lifestyle}

Approaching leisure time in terms of lifestyle is one of the newest developments in the science of leisure since the 1980s. In this light, it is possible to record together the many detailed results of leisure science on leisure styles. At this point, one must distinguish between two important aspects of approach: firstly, approaching lifestyle as a determinant of leisure time, secondly, approaching leisure time as part of the lifestyle. For these two approaches, the concept of leisure style was created. Lifestyle in a nutshell can be understood as a thematically structured model of providing motivation, perceptions, behaviour and experience in order to meet needs, accomplish tasks, and reach or achieve goals. Leisure style can be considered the domain, which refers to the variables that are oriented to leisure within a lifestyle, so that leisure style is the way in which these variables are applied to an individual or a social group in the provision of motivations, perceptions, behaviours, and experiences (TOKARSKI \& SCHMITZ-SCHERZER, 1985).

Life and leisure time styles are difficult to record methodically, because ultimately all variables referring to individuals, the environment and society should be included in the analysis. Thus, in the science of leisure time and in particular in the psychology of leisure, two approaches are preferred: on the one hand the development of the "pragmatic leisure style models" referring to the narrowest object (TOKARSKI, 1992) and on the other the development of leisure typologies. Pragmatic leisure style models limit the set of potential leisure style variables to central domain analysis, such as e.g. time structures, spatial configurations, social networks and / or consumer patterns, which can then be analysed independently or in combination with each other in terms of motivation, perceptions, behaviours and experiences. Thus, the totality of the concept of leisure style with a comprehensive multidimensional addition is contrasted with a functionality construct that is confined to "central" aspects. Leisure typologies try, particularly in the context of personality psychology, to obtain, based on certain laws, specific personality characteristics of the syndrome type, to associate them with leisure variables and thus, based on parameter analytic procedures, to create leisure types. People today no longer act in accordance with the old sociological paradigm, where there was a given world in which the ego had to adapt. The perception of the relationship between the ego and the world clearly follows a new paradigm: Even if something is taken for granted, that is the ego. The world has to adapt, which in an incredibly short period of time has equipped itself in an environment of as many random desires as possible (SCHULZE, 2002). This change from the subject that refers to the world that refers to the subject applies more or less to all societies. Everywhere in the world the modern era is characterized by the attitude to life: "I do what I like". In some societies this is still seen as a sign of rebellion, breaking taboos and denying social structures - nevertheless it is already widespread. But in Western societies it has already become a subject that is constantly debated. All people have the opportunity to shape their lives as they wish. The more democratic a society, the greater the number of options available, and different paths can be proposed to achieve a life that is satisfying to everyone. Especially for leisure time behaviour, many people have new perspectives, new social relationships, and new lifestyles. But looking at leisure-oriented lifestyles shows that these new possibilities cannot be exploited independently of socially unequal starting positions. From the aspect of social sciences, it has been shown that lifestyle expression depends on demographic factors that are not influenced, such as age and gender, as well as social factors such as education, occupational status and income. Therefore, according to the paradigm that refers to the subject, which leads to the fact that humans are capable of all the possibilities available to distinguish the pieces of the puzzle that suits them, these social inequalities have not disappeared, but rather remain hidden. The various manifestations of lifestyles express the increasing choice and the diminishing coercion of modern society as defined by people in new patterns of classification. These new classification patterns reflect the social strata that each one belongs to as a "lifestyle". This has resulted in 'social inequalities becoming invisible, since lifestyles appear to have been freely chosen "(SPELLERBERG, 1996). With the ability to position oneself, as to the composition of a certain lifestyle, in yet another social field, the permeability of social strata has increased. Thus, it might not be the case for all people, but for many in the first step applies the phrase "I do what I want" and in the second step the phrase "I will overcome social inequalities". In this context, the formation of leisure time plays an important role, because lifestyle is developed centred on the relatively free-form areas of life - hence on the area of leisure time -. In our view, the discussion of this position is of particular importance for the development of a 'European Community' with its own identity, because: the more modern a society is, the greater the opportunities for people to transcend social limits with lifestyle education'. Greater modernization would enable them to obtain new individual opportunities and perspectives for shaping their 
lives, which so far have not been accessible to them. Therefore, the discussion on 'leisure time and lifestyle' is not only a reflexive discussion about processes of structural and social change that have already taken place, but is also an important discussion of future individual opportunities for social change in Europe. Human behaviour in modern Europe with regard to leisure time is often misrepresented in a trivial way: in Germany people, after work, wear their slippers and sit in front of the TV drinking beer, in Italy they sit in cafes, drinking cappuccino and reading 'Gazetto dello Sport', and in Poland they don't know what free time is because all people constantly sell or buy anything cheap. Neither personal experiences nor statistical surveys are able to give us a realistic picture of the complex patterns of behaviour in free, without work, time.

From the point of view of social and politics sciences, in Germany - and this is certainly also true for other countries such as Great Britain and France - a worrying picture of leisure time is currently being described: the population spends leisure time doing nothing "skilful", and is rather passive generally. People watch too much television and most of the young people are at risk of overusing the media, especially computer games. In fact, according to the Eurobarometer (2002) it was found that almost all Europeans watch television, $99 \%$ have at least one television set and $88.9 \%$ of respondents prefer to watch news. Movies follow right after $(84.3 \%)$, and only half of the Europeans prefer to watch sports on television $(50.3 \%)$. Sixty percent of Europeans listen to the radio daily and, in particular, they listen to music $(86.3 \%)$. Now, as regards computers and the Internet: $53.3 \%$ of the Europeans do not have a computer. This is mainly the case in Greece (75.3\%) and Portugal (74.7\%), while in Sweden, Denmark and the Netherlands over $30 \%$ of the respondents reported using a computer daily. This is not the case in the workplace, but throughout Europe the computer is mainly used at home in leisure time to communicate with friends via e-mail $(57.8 \%)$, to search for information on sports topics and leisure opportunities $(33.2 \%)$ or for planning and booking the next holiday trip $(30.8 \%)$. What do people in Europe do when they are not sitting in front of a television or a computer? They read: almost half of the Europeans read a daily newspaper (46\%). This average is significantly higher in Finland, Sweden, Germany and Luxembourg, where respectively $77.8 \%$, $77.7 \%, 65.5 \%$ and $62.7 \%$ of the citizens read daily newspapers. The analysis of reading behaviour for each country also shows that in northern European countries reading books is an important leisure time activity. For example, in Sweden $71.8 \%$ of the population reads out of school and work, while in Belgium 58.3\% and in Portugal $67.3 \%$ of the respondents have not read a single book in the past 12 months. But also, with regard to other cultural activities such as cinema, use of libraries, attendance of pop concerts and classical music, the populations of Portugal and Greece show little interest compared to the other countries of the European Union. In these two countries, on the other hand, they attend sports events and traditional music concerts more frequently than the European Union average. Eurobarometer statistics clearly show that in Europe consumer-oriented activities are much more represented than artistic activities. Particularly impressive is the large percentage of Europeans that have never participated in a theatrical play (94\%), that play no musical instruments $(86.8 \%)$ and furthermore do no other activities such as painting, drawing, writing, singing or dancing. On the basis of these data, there is always the risk of creating an impression of 'leisure time' that is not realistic. The fact that $99 \%$ of the European citizens own a television set initially simply states that these devices exist in their homes. From the findings we learn nothing about the completely different way of operation and use, about the position of television in the activity profile of the individual and about specific groups (young people, family, the elderly, etc.). Shell's study about young people (DEUTSCHE SHELL, 2003) shows, e.g. for Germany, that there are large differences in leisure time employment between girls and boys, between young and old, between lower and higher secondary school students, between working young people and college students, and of course between East Germans and West Germans. As regards the average of all young people in Germany, at the peak of their leisure time employment, with $62 \%$, is meeting people. Next come television (58.5\%), leisure time sports $(31.5 \%)$ and club sports, online surfing and book reading, all of which are preferred by about a quarter of the young people. In all of these elements it is worth noting that empirical findings can give a very different picture of leisure time. Research results that are produced for a certain interest are often circulated. Most studies are consumer surveys or market research surveys, studies of the private economy or of economic links that have an economic background. With respect to science, this means that empirical data must be used responsibly and for the economy at least it indicates that leisure sector is still booming. Because huge financial resources in market research can only be invested in a prosperous financial sector (ZAROTIS et al., 2011).

\section{CONCLUSION}

Leisure time behaviour is the broader concept of individual aspects such as activities or actions during leisure time, the shaping of leisure time and the model of leisure time. Regarding these individual aspects, we can say the following: All of the individual activities in conjunction with the frequency they are performed each time give nothing more than their potential and their relative importance in shaping leisure time. Leisure time activities are therefore characteristic measures of the socially acceptable range of behaviours in a society, class or group with respect to leisure. Examination of leisure time biographies shows that leisure time activities and patterns change significantly over the course of life. The decisive factors of the increasing value of leisure time are called demographic changes. For example, increasing life expectancy affects the demographic makeup of society and therefore leisure time. In fact, this means the following: Increasingly older people have the opportunity to actively use their leisure time for even longer. This demographic shift is reflected in the quality of leisure offerings because older people want to spend their leisure time differently than younger people (OPASCHOWSKI, 2012). With the ability to put oneself even in another social environment regarding 
the composition of a certain way of life, the permeability of the social strata has increased. In the social sciences it is undisputed (as previously shown by the creation of the theory) that certain lifestyles were shaped significantly in relation to social status. On the contrary, it is also accepted that lifestyles should not be regarded only as dependent variables, but could also serve as declarative dimensions: For example, in order to state a different type of well-being, SPELLERBERG (1996) found among other things that in East Germany a person whose lifestyle is "hedonistically oriented towards leisure time", also characterized as "an athlete oriented towards leisure time", is the winner type. This type of person looks very optimistic, satisfied and can orient himself well into a new social environment. Undoubtedly not all people have been able to cope with the intensity of social change and the compulsion to integrate into a new social system: Empirical studies show, in part, that lifestyle groups characterized by high living standards, orientation towards work, information and having a great deal of the same experience, have enormous problems in adapting to new circumstances - while people for whom youthful attire is more important than education, and fun and leisure are more important than social participation, have no adaptation problems. Overall, there is a continuing interest in answering questions in the field of leisure time and lifestyle: politicians seek answers to the question of the 21st Century's 'pioneering figure', the economy seeks new trends and opportunities for the expanding experience industry, and science is trying to empirically discover and document a new "existential mix" of work and leisure time, education and voluntary participation (DGF, 1995, 2000).

\section{REFERENCES}

Agricola, S., Haag, A. \& Stoffers, M. (1990). Freizeitwirtschaft. Maerkte und Konsumwelten (Kongress: Freizeit-Wirtschaft und Konsum vom 1.-4.10.1989 in Wuppertal). Erkrath/Wuppertal: Deutsche Gesellschaft fuer Freizeit.

Deutsche Shell (Hrsg.) (2003). Jugend 2002 - 14. Shell Jugendstudie. Frankfurt/Main: Selbstverlag.

Dietrich, K., Heinemann, K. \& Schubert, M. (1990). Kommerzielle

Sportanbieter - Eine empirische Studie zu Nachfrage, Angebot und

Beschaeftigungschancen im privaten Sportmarkt. Schorndorf: Hofmann.

DGF-Deutsche Gesellschaft fuer Freizeit (1995). Freizeit in Deutschland 1995. Erkrath: Deutsche Gesellschaft fuer Freizeit.

DGF-Deutsche Gesellschaft fuer Freizeit (1998). Freizeit in Deutschland '98. Erkrath: Deutsche Gesellschaft fuer Freizeit.

DGF-Deutsche Gesellschaft für Freizeit (2000). Freizeit in Deutschland. Freizeittrends 2000plus (Ergaenzungsband zum DGFJahresgutachten). Erkrath: Deutsche Gesellschaft fuer Freizeit.

Eurobarometer (2002). Die Beteiligung der Europaeer an kulturellen Aktivitaeten. Bruessel: Selbstverlag.

Freyer, W. (2002). Handbuch des Sportmarketing. Wiesbaden: Forkel.

Freyer, W. (2001). Sport und Tourismus - Megamaerkte in der wissenschaftlichen Diskussion. In: Trosien, G. \& Dinkel, M. (Hrsg.) Sport-Tourismus als Wirtschaftsfaktor. Butzbach: Bundesverband Wassersportwirtschaft e. V., 32-65.

Frogner, E. (1991). Sport im Lebenslauf. Eine Verhaltensanalyse zum Breiten- und Freizeitsport. Soziologische Gegenwartsfragen, N.F., Nr. 50. Stuttgart: Enke.

Fuchs, W. et al. (Hrsg.) (2011). Lexikon zur Soziologie. Wiesbaden: VS Verlag für Sozialwissenschaften.

Heinemann, K. (1989). Der „Nicht-sportliche Sport“ In: Dietrich, K. \& Heinemann, K. (Hrsg.): Der nicht-sportliche Sport. Schorndorf: Hofmann, 11-28.

Freericks, R. \& Brinkmann, D. (Hrsg.) (2015). Handbuch Freizeitsoziologie. Wiesbaden: VS Verlag für Sozialwissenschaften.
Opaschowski, H. W. (2012). Freizeitoekonomie: Marketing von Erlebniswelten. Wiesbaden: VS Verlag für Sozialwissenschaften.

Opaschowski, H. W. (2008). Einfuehrung in die Freizeitwissenschaft (5. Aufl.). Wiesbaden: VS Verlag für Sozialwissenschaften.

Rittner, V., Mrazek, J. \& Meier, R. (1989). Sportinfrastruktur im Kreis Neuss. Koeln: Deutsche Sporthochschule Koeln.

Schulze, G. (2002). Die Erlebnisgesellschaft. Kultursoziologie der Gegenwart. Frankfurt/Main, New York: Campus.

Spellerberg, A. (1996). Soziale Differenzierung durch Lebensstile. Eine empirische Untersuchung zur Lebensqualitaet in West- und Ostdeutschland. Berlin: Sigma

Statistisches Bundesamt (1994). Wo bleibt die Zeit? Die Zeitverwendung der Bevoelkerung in Deutschland. Wiesbaden: Selbstverlag.

Roberts, K., Minten, J. H., Chadwick, C. et al. (1991). Sporting lives: a case study of leisure careers. In: Society and Leisure 14,1 .

Tokarski, W. \& Schmitz-Scherzer, R. (1985). Freizeit. Stuttgart: B. G. Teubner.

Tokarski, W. (1988). Freizeit im Lebensverlauf - eine bisher vernachlaessigte Perspektive. In: Fromme, J. \& Stoffers, M. (Hrsg.): Freizeit im Lebensverlauf. Bielefeld: IFKA-Schriftenreihe.

Tokarski, W. (1989). Freizeit und Lebensstile aelterer Menschen. In: Kasseler Gerontologische Schriften, Heft 10. Kassel: UniversitaetGHS.

Tokarski, W. (1992). Institut fuer Freizeitwissenschaft an der Deutschen Sporthochschule Koeln. In: Freizeitpaedagogik - Forum fuer Kultur, Medien, Sport, Tourismus 14, 2.

Tokarski, W. (1995a). Geaendertes Freizeitverhalten der Jugendlichen und Auswirkungen auf die Schule. REALSCHULLEHRERVERBAND NRW (Hrsg.): Medienkonsum und Freizeitverhalten von Jugendlichen. Duesseldorf: Selbstverlag.

Wachenfeld, H. (1989). Freizeitmarketing - die Versorgung der Freizeitgesellschaft mit Guetern. In: Verbraucher-Zentrale NRW (Hrsg.): Freizeit und Konsum. Duesseldorf: Selbstverlag.

Zarotis, G., Tokarski, W., Kontakos, A., \& Katsagolis, A. (2011). Free time. Physical activity, Health and Quality of Life. Athen/Zefyri: Diadrasi.

Dr. George F. Zarotis is a lecturer at the Faculty for Human Sciences of the Aegean University in Rhodes/Greece since 2004. He studied sports science at the German Sport University in Cologne as well as prevention and rehabilitation through sport at the Ruhr-University Bochum (Master Degree). Furthermore, he studied sports economics and sports management at the Open University Hagen. He achieved the Doctorate in the subjects of leisure science and rehabilitation at the German Sport University Cologne $(\mathrm{PhD})$. He started his academic career as lecturer at the Institute for European Sports Development and Leisure Research of the German Sport University Cologne and at the University of Applied Sciences for Applied Management in Unna. Mr. Zarotis has published a number of books and scientific articles dealing with education, management, kinetic education, psychology of sports and health studies in Greece and internationally. In $2020 \mathrm{Mr}$. Zarotis received the International Research Leadership Award as "International Distinguished Researcher in Recreational Sport, Leisure and Health Studies". 